\title{
Transgender health and its current omission from medical school curriculum: medical students' perspective
}

This article was published in the following Dove Press journal:

Advances in Medical Education and Practice

\author{
Samantha James \\ Helena Colling Sylvester \\ Cardiff Medical School, Cardiff \\ University, Cardiff, UK
}

Correspondence: Samantha James School of Medicine, University Hospital Wales Main Building, Heath Park, Cardiff, CFI 4 4XN, UK

Email jamess35@cardiff.ac.uk

\section{Dear editor}

We read with great interest the article by Dubin et al, ${ }^{1}$ which highlighted a widespread issue in the lack of transgender health exposure among both undergraduate and postgraduate curricula. As final-year, UK medical students, we would like to offer our perspective on transgender-related health education.

We are delighted to see a thorough review on the current state of transgender-specific education. However, we were disappointed to read that due to its exclusion from the medical curricula, we directly contribute to health inequalities experienced by the transgender population. Furthermore, we acknowledge a recent and important study, which reports that $41 \%$ of the transgender population attempt suicide at least once during their lifetime. ${ }^{2}$ While we recognize that a lack of curricular time may constrain the ability to teach the many topics within transgender medicine, we firmly believe that this statistic alone should highlight the seriousness of this curricula oversight. We fully support the notion that sufficient transgender medical education must begin in medical school and continue throughout our careers.

We agree with the recommendations of the article that accreditation boards alike should specifically name transgender health as a required topic while simultaneously identifying clinical competency expectations. In 2018, the UK's Medical Students Conference acknowledged inadequate training on this topic and called upon the British Medical Association to investigate current levels of training and lobby the Medical Schools Council, General Medical Council, and Royal Colleges to ensure transgender health care becomes a core part of undergraduate and postgraduate training. ${ }^{3} \mathrm{We}$ strongly believe that pressure needs to be put on curricula influencers in order to rectify the current omission.

As final-year medical students, we have had no teaching on transgender healthrelated issues beyond equality and diversity sessions. From our experience, anxiety stems from a lack of understanding of gender pronouns; misgendering a patient can have hugely negative impacts on the individual and their willingness to seek help again.

We believe that the transgender community is best able to educate medical professionals in how to create an environment which adequately responds to their needs. We believe that initiating a discussion will help to bridge the gap between the current disparities in transgender care. Furthermore, involving common transgender-related scenarios in communication skills training would provide opportunities for students 
to practice key skills, such as correct terminology, in a supporting environment to ensure that they are confident and competent when they graduate. Role-play and communication skills teaching improve the competencies of medical students, and $90 \%$ of students communicate better after such training. ${ }^{4}$ We effectively use this principle in other areas of medicine, so, it should also be used to improve competency in transgender-related health.

We agree with the difficulties highlighted in Dubin et $\mathrm{al}^{1}$ that current research does not allow us to reach a consensus as to the most effective interventions. However, perhaps more importantly, this paper demonstrated that all interventions were associated with some level of improvement in attitudes, skills, and knowledge. Therefore, we can no longer accept nor allow a complete lack of medical curricula time to continue to reinforce barriers to an already marginalized population.

\section{Disclosure}

The authors report no conflicts of interest in this communication.

\section{References}

1. Dubin SN, Nolan IT, Streed CG Jr, Greene RE, Radix AE, Morrison SD. Transgender health care: improving medical students' and residents' training and awareness. Adv Med Educ Pract. 2018;9:377-391.

2. Smith JR, Morrison SD, Gottlieb LJ. Are surgical residents prepared for fellowship training in gender-confirming surgery? J Sex Med. 2017;14(8):1066-1067.

3. Morrison SD, Smith JR, Mandell SP. Are surgical residents prepared to care for transgender patients? JAMA Surg. 2018;153(1):92-93.

4. Morrison SD, Wilson SC, Smith JR. Are we adequately preparing our trainees to care for transgender patients? J Grad Med Educ. 2017;9(2):258. 


\section{Authors' reply}

Ian T Nolan'

Samuel Dubin'

Shane D Morrison ${ }^{2}$

'New York University School of Medicine, New York, NY, USA; ${ }^{2}$ Division of Plastic Surgery, Department of Surgery, University of Washington, Seattle, WA, USA

Correspondence: Shane D Morrison

Division of Plastic and Reconstructive Surgery, Department of Surgery, Harborview Medical Center, 325 9th Avenue, Mailstop \#359796 Seattle, WA 98104, USA

Email shanedm@uw.edu

\section{Dear editor}

We thank the authors for their correspondence to our article. ${ }^{1}$ They raised a well-taken point that the lack of transgender health education is not limited to the USA and Canada, which encompassed the geographic scope of our review. We appreciate their insight into the lack of transgender health education in the United Kingdom's various medical education curricula. We are encouraged by the UK's Medical Students Conference lobbying efforts to promote the topic in medical schools.

We hope our review will encourage similar reviews of transgender health education in other health education systems. Such efforts are needed, especially in medical education systems that differ from the traditional 4-year medical school programs predominantly in the United States, in order to determine which specific educational interventions are most effective in increasing attitudes, skills, and awareness of transgender health issues in non-US medical systems. Due to our review's scope, we cannot claim that all our recommendations are applicable to foreign educational systems. However, we do encourage medical education programs in other nations to adopt relevant recommendations for their respective educational systems. ${ }^{2-4}$ Medical education is a cornerstone of equitable health care for transgender patients regardless of where they live.

\section{Disclosure}

The authors report no conflicts of interest in this communication.

\section{References}

1. Dubin SN, Nolan IT, Streed CG Jr, Greene RE, Radix AE, Morrison SD. Transgender health care: improving medical students' and residents' training and awareness. Adv Med Educ Pract. 2018;9:377-391.

2. Smith JR, Morrison SD, Gottlieb LJ. Are surgical residents prepared for fellowship training in gender-confirming surgery? $J$ Sex Med. 2017;14(8):1066-1067.

3. Morrison SD, Smith JR, Mandell SP. Are surgical residents prepared to care for transgender patients? JAMA Surg. 2018;153(1):92-93.

4. Morrison SD, Wilson SC, Smith JR. Are we adequately preparing our trainees to care for transgender patients? J Grad Med Educ. 2017;9(2):258.

\begin{abstract}
Dove Medical Press encourages responsible, free and frank academic debate. The content of the Advances in Medical Education and Practice 'letters to the editor' section does not necessarily represent the views of Dove Medical Press, its officers, agents, employees, related entities or the Advances in Medical Education and Practice editors. While all reasonable steps have been taken to confirm the content of each letter, Dove Medical Press accepts no liability in respect of the content of any letter, nor is it responsible for the content and accuracy of any letter to the editor.
\end{abstract}

\section{Publish your work in this journal}

Advances in Medical Education and Practice is an international, peerreviewed, open access journal that aims to present and publish research on Medical Education covering medical, dental, nursing and allied health care professional education. The journal covers undergraduate education, postgraduate training and continuing medical education including emerging trends and innovative models linking education, research, and health care services. The manuscript management system is completely online and includes a very quick and fair peer-review system. Visit http://www.dovepress.com/testimonials.php to read real quotes from published authors. 